\title{
Atherogenic Index Profile on Ischemic Stroke Patients at Neurology Department, Dr. Soetomo Surabaya: A Retrospective Study
}

\author{
Shita Febriana ${ }^{1}$, Mohammad Saiful Ardhi ${ }^{2}$ \\ ${ }^{1}$ Resident of Neurology Department on Medical Faculty Airlangga University-Dr.Soetomo General Hospital \\ Surabaya Indonesia \\ ${ }^{2}$ Staff of Neurovascular Division of Neurology Department on Medical Faculty Airlangga University- \\ Dr.Soetomo General Hospital Surabaya Indonesia \\ Corresponding Author: Shita Febriana
}

\begin{abstract}
Stroke was associated with morbidity and mortality in the world. Lipid index discovered through lipid profile tests may be used as a predictor in vascular diseases. To increase the prediction value of lipid profile to stroke outcome, several lipoprotein ratios, called atherogenic index, were still being researched. Atherogenic indexes included Atherogenic index of plasma, Castelli Risk Index I and II, atherogenic coefficient, and non-high density lipoprotein cholesterol. The aim of this study is to find atherogenic index profile as a marker for atherogenicity on acute ischemic stroke patients at Neurology Department Dr. Soetomo hospital from January-September 2019.

This is a retrospective descriptive of 65 patients on stroke registry. Data collected including low and high AIP level on 19, 46 patients, respectively; low CRI I on 22 patients and high CRI I on 43 patients; low CRI II from 31 patients and high CRI II from 34 patients; low and high AC on 9 and 56 patients, respectively; also, low NHC on 21 patients and high NHC on 44 patients. Poor outcome on outpatient was identified in 30 patients (NIHSS $>7$ )

This study indicates most ischemic stroke patients have high atherogenic index level. Analysis on the differences between lipid index and NIHSS poor outcome revealed AC and NHC level were significant with $\mathrm{p}=0,031$, CI $8,593(1,007-73,319)$ and $p=0,01$, CI 9,529 $(2,435-37,3)$, respectively.
\end{abstract}

Keywords: atherogenic index, ischemic stroke, NIHSS

\section{INTRODUCTION}

Stroke is a condition caused by the disruption of blood flow to the brain, indicated by focal or global neurologic deficit happened more than 24 hours or died before 24 hours and other causes have been eliminated. Stroke is the cause of high mortality and morbidity in the world. Generally, in the last two and a half decades, there is a significant increase of stroke incident, especially in developing countries ${ }^{1}$. Data from Riskesdas Indonesia 2018 stated highest stroke prevalence was at East Kalimantan (14,7/1000), East Java on the $8^{\text {th }}$ rank, are still higher than national prevalence $(10,9 / 1000)^{3}$.

Indonesia Stroke Registry 2013 noted $67.1 \%$ stroke cases was ischemic stroke and $32.9 \%$ was due to hemorrhage. There were 2 types of risk factors for ischemic stroke which are modifiable and non-modifiable factors. Non-modifiable factors such as age, gender, and genetic. Modifiable factors for example hypertension, diabetes, smoking, and hyperlipidemia. One of risk factors for ischemic stroke is dyslipidemia which causes ischemic stroke through atherosclerosis. Identifying ischemic stroke risk factor is important to control ischemic 
Shita Febriana et.al. Atherogenic index profile on ischemic stroke patients at neurology department, Dr Soetomo Surabaya: a retrospective study.

stroke incidence in a country. Pinpointing risk factors associated with ischemic stroke enabling preventive actions. ${ }^{9}$ Lipid serum abnormality may increase the risk of ischemic stroke up to $50 \%$ compared to normal. ${ }^{7}$

Patients were diagnosed based on National Cholesterol Education Program Adult Treatment Panel III (NCEP-ATP III) which consists total cholesterol (TC) $>240$ $\mathrm{mg} / \mathrm{dL}$, low density lipoprotein cholesterol $(\mathrm{LDL}-\mathrm{C})>160 \mathrm{mg} / \mathrm{dL}$, high density lipoprotein cholesterol (HDL-C) $<40$ $\mathrm{mg} / \mathrm{dL}$ in male or $<50 \mathrm{mg} / \mathrm{dL}$ in female, triglyceride (TG) $>200 \mathrm{mg} / \mathrm{dL}$ (Garg et al., 2015). Cholesterol-lowering medication gave a depiction on declining of stroke and carotid atheroma risk. This showed lipid level abnormality is associated with pathophysiology and clinical outcome of stroke patients. This study indicated that lipid index calculated from lipid profile is a better predictor for cardiovascular diseases.

To increase predictor value of lipid profile to stroke outcome, several lipoprotein ratios, called atherogenic index, started to be studied. Previous studies stated lipid index was related to an increase of cardiovascular risk. Atherogenic index mentioned were Atherogenic index of plasma, Castelli Risk Index I and II, atherogenic coefficient (AC), and non-high density lipoprotein cholesterol (NHC). ${ }^{10}$

\section{METHODS}

\section{Study Design}

This study used a cross sectional design with the research subjects being patients with acute thrombotic stroke who were treated in the Nervous Room at RSUD Dr. Soetomo in the period July 2019 to Nov 2019. who met the inclusion and exclusion criteria. Inclusion criteria were patients with acute thrombotic stroke, first attack, age > 18 years, and complete medical record data. While the exclusion criteria were stroke patients with infections, tumors, myocardial infarction, and the use of statins or fibrates

Patients with acute thrombotic stroke who met the inclusion and exclusion criteria underwent anamnesis, neurological physical examination, CT scan supporting examination, then lipid profile examination and NIHSS examination were performed. The NIHSS examination uses medical record data.

The size of the research subjects was determined by the sample size formula for the correlative analysis test with a type 1 error of $5 \%$ and a type II error of $20 \%$ and the number of research subjects was 65 research subjects. Statistical analysis used SPSS 24. Statistical analysis was performed with SPSS 24.0.

\section{RESULTS}

\section{Subjects' Characteristics}

Baseline characteristic included age and gender as shown on table 1.1 and 1.2.

Table 1.1 Subjects' characteristics based on gender

\begin{tabular}{|l|l|l|}
\hline Subjects' characteristics & \multicolumn{2}{|l|}{ Ischemic stroke frequency } \\
\hline Gender & Amount (n) & Percentage (\%) \\
\hline Male & 38 & 58 \\
\hline Female & 27 & 42 \\
\hline Total & $\mathbf{6 5}$ & $\mathbf{1 0 0}$ \\
\hline
\end{tabular}

Table above depicted ischemic stroke patients based on gender. Most of patients were male (58\%), followed by female (42\%).

Table 1.2 Subjects' characteristics based on age

\begin{tabular}{|l|l|l|}
\hline Subjects' characteristics & \multicolumn{2}{|l|}{ Ischemic stroke frequency } \\
\hline Age (year) & Amount (n) & Percentage (\%) \\
\hline$\leq 60$ & 30 & 46.15 \\
\hline$>60$ & 35 & 53.85 \\
\hline Total & $\mathbf{6 5}$ & $\mathbf{1 0 0}$ \\
\hline
\end{tabular}

Based on table 4.2, ischemic stroke patients were mostly aged $\leq 60$-year-old (46.15\%), while $>60$-year-old was $53.85 \%$.

\section{Atherogenic Index Profile Examination}

Table 1.3 until 1.7 described the atherogenic index examination as followed:

Table 1.3 Subjects' characteristics based on AIP (Atherogenic Index of Plasma)

\begin{tabular}{|l|l|l|}
\hline Subjects' characteristics & \multicolumn{2}{|l|}{ Ischemic stroke frequency } \\
\hline AIP & Amount (n) & Percentage (\%) \\
\hline Low & 19 & 30 \\
\hline High & 46 & 70 \\
\hline Total & $\mathbf{6 5}$ & $\mathbf{1 0 0}$ \\
\hline
\end{tabular}

Based on table 1.3, subjects with low AIP were 19 subjects (30\%) and high 46 subjects (70\%). Analysis on the differences 
Shita Febriana et.al. Atherogenic index profile on ischemic stroke patients at neurology department, Dr Soetomo Surabaya: a retrospective study.

between AIP and NIHSS poor outcome (NIHSS $>7$ ) is $\mathrm{p}=0,53$.

Table 1.4 Subjects' characteristics based on CRI I (Castelli Risk Index I)

\begin{tabular}{|l|l|l|}
\hline Subjects' characteristics & \multicolumn{2}{|l|}{ Ischemic stroke frequency } \\
\hline CRI I & Amount (n) & Percentage (\%) \\
\hline Low & 22 & 33 \\
\hline High & 43 & 67 \\
\hline Total & $\mathbf{6 5}$ & $\mathbf{1 0 0}$ \\
\hline
\end{tabular}

Based on table 4.4, there were 22 subjects (33\%) with low CRI I value and 43 (67\%) subjects with high value. Analysis on the differences between CRI I and NIHSS poor outcome (NIHSS $>7$ ) is $\mathrm{p}=0,3$.

Table 1.5 Subjects' characteristic based on CRI II (Castelli Risk Index II)

\begin{tabular}{|l|l|l|}
\hline Subjects' characteristics & \multicolumn{2}{|l|}{ Ischemic stroke frequency } \\
\hline CRI II & Amount (n) & Percentage (\%) \\
\hline Low & 30 & 46 \\
\hline High & 35 & 54 \\
\hline Total & $\mathbf{6 5}$ & $\mathbf{1 0 0}$ \\
\hline
\end{tabular}

Based on table 1.5 , there were 30 subjects (46\%) with low CRI II value and 35 subjects (54\%) with high CRI II value. Analysis on the differences between CRI II and NIHSS poor outcome (NIHSS $>7$ ) is $\mathrm{p}=$ 0,62 .

Table 1.6 Subjects' characteristics based on AC (Atherogenic Coefficient)

\begin{tabular}{|l|l|l|}
\hline Subjects' characteristics & \multicolumn{2}{|l|}{ Ischemic stroke frequency } \\
\hline AC & Amount (n) & Percentage (\%) \\
\hline Low & 9 & 14 \\
\hline High & 56 & 86 \\
\hline Total & $\mathbf{6 5}$ & $\mathbf{1 0 0}$ \\
\hline
\end{tabular}

Based on table 1.6, low and high AC value were detected in $9(14 \%)$ and 56 (86\%) subjects, respectively. Analysis on the differences between AC and NIHSS poor outcome (NIHSS $>7$ ) is $\mathrm{p}=0,031$.

Table 1.7 Subjects' characteristics based on NHC (Non-High Density Lipoprotein Cholesterol)

\begin{tabular}{|l|l|l|}
\hline Subjects' characteristics & \multicolumn{2}{|l|}{ Ischemic stroke frequency } \\
\hline NHC & Amount (n) & Percentage (\%) \\
\hline Low & 21 & 32 \\
\hline High & 44 & 68 \\
\hline Total & $\mathbf{6 5}$ & $\mathbf{1 0 0}$ \\
\hline
\end{tabular}

Low NHC was obtained by 21 subjects (32\%) while high level was acquired by 44 subjects (68\%) as listed in table 1.7. Analysis on the differences between AIP and NIHSS poor outcome (NIHSS $>7$ ) is $\mathrm{p}=0,001$.

\section{DISCUSSION}

In this study, most ischemic stroke patients were male patients compared to female ( $58 \%$ vs $42 \%)$. Similar gender proportion was also reported by Siswonoto, 33 where $69.8 \%$ subjects were male while the rest (30.2\%) were female. A study at Raden Mattaher hospital also reported analogous percentage of $56.79 \%$ vs $43.20 \%$ for male and female, respectively. Male has a 1.25 higher risk to develop ischemic stroke compared to female. This was due to estrogen in female before menopause. Estrogen protects blood vessels from atherosclerosis process that may cause thrombotic stroke event.

All subjects were divided into two age groups, $\leq 60$-year-old and $>60$-yearold. Subjects aged $\leq 60$-year-old was more than > 60-year-old which $46.15 \%$ vs $53.85 \%$. The risk for a stroke event was twice higher after 550year-old. In male patients, the risk of stroke was between 45 to 84-year-old. This is due to several factors, such as plaque accumulation on artery causes atherosclerosis and, therefore, ischemic stroke.

Calculations of various lipid ratios and indices may show the existence of association if any. These indices include AIP, CRI, AC, and NHC.

According to table $1.3-1.7$, low AIP value was observed in 3 subjects (5\%), medium in 16 subjects (25\%), and high in 46 (70\%); low CRI I in 22 subjects (33\%) and high in 43 (67\%); CRI II was found low in 30 subjects (46\%) and high in 35 subjects (54\%); AC value was discovered low in 9 (14\%) and high in 56 subjects (86\%); low and high NHC value was obtained in 21 subjects (32\%) and 44 subjects (68\%), respectively. These results showed atherogenic index profile in acute ischemic stroke patients in Dr Soetomo hospital was high. This is similar with previous study describing atherogenic index was significantly high in stroke patients.

This study indicates most ischemic stroke patients have high atherogenic index level. Analysis on the differences between 
Shita Febriana et.al. Atherogenic index profile on ischemic stroke patients at neurology department, Dr Soetomo Surabaya: a retrospective study.

lipid index and NIHSS poor outcome revealed $\mathrm{AC}$ and $\mathrm{NHC}$ level were significant with $\mathrm{p}=0,031$, CI 8,593 (1,007 $73,319)$ and $\mathrm{p}=0,01$, CI 9,529 (2,435 37,3), respectively. his finding was consistent with the study by $\mathrm{Wu}$, et al, Zhang et al and Sujatha et al.

\section{CONCLUSION}

In the present study, the atherogenic lipid indices were significantly higher in stroke patients compared to controls. Two indices AC, and NHC were found to be contributing to the risk of stroke significantly. These can be easily estimated from routinely done parameters and is therefore a cheaper alternative to other costly diagnostic tests and modalities. The inclusion of these indices in routine clinical setup may help to identify at risk individuals and guide effective treatment modalities in stroke patients

\section{Suggestions}

This study is a cross-sectional study with a small sample size and short study duration. Therefore, further study with bigger sample size and longer duration is needed to be able to give a more accurate result.

\section{Acknowledgement: None}

\section{Conflict of Interest: None}

\section{Source of Funding: None}

\section{REFERENCES}

1. Benjamin EJ, Blaha MJ, Chiuve SE, Chusman M, Das SR, Deo R,et al. 2017. Heart Disease and Stroke Statistic-2017 Update: A Report From the American Heart Association. Circulation 135(12):67-492. Doi:10.1161/CIR.00000000000 00485.

2. Grotta JC, Albers GW, Broderick JP, et al. 2016. Stroke: Pathophysiology, Diagnosis and Management. Elsevier Health Sciences: 164

3. Kanyal N. 2015. The Science of Ischemic Stroke: Pathophysiology \& Pharmaco logical Treatment. International Journal of Pharma Research \& Review 4(10): 65-84.

4. Harris S. 2012. The Association of Carotid Media Intima Thicknessand Stroke: A Cross Sectional Study. Perspective in Medicine 1:164-166. Doi: $\quad 10.1016 / j . p e r$ med.2012.04.007.

5. Okazaki S, Sakaguchi M, Miwa K, Furukado S, Yamagami H, Yagita Y, et al. 2014. Association of Interleukin-6 with The Progression of Carotid Atherosclerosis: A 9 Year Follow Up Study. Stroke 45:2924-9. Doi:10.1161/ STROKEAHA.114.005991.

6. Zhang B, Wang J, Xu Y, Zhou X, Liu J, Xu Jing, et al. 2014. Correlative Association of Interleukin-6 with Intima Media Thickness: A Meta-Analysis. Int J Clin Exp Med 8(3): 4731-3.

7. Reiss AB, Siegart NM, Leon JD. 2017. Interleukin-6 in Atherosclerosis: Atherogenic or Atheroprotective?. Clinical Lipidology 12(1): 14-23. Doi:10.10 80/17584299.201 7.1319787

8. Harris S, Sungkar S, Al-Rasyid, Kurniawan M, Mesiano T, Hidayat R. 2018. TOAST Subtypes of Ischemic Stroke and Its Risk Factors: A Hospital-Based Study at Cipto Mangunkusumo Hospital Indonesia. Stroke Research and Treatment. Doi:10.1155/2018/9589831

9. Choudry MS, Chowdhury MD, Nayeem A, Jahan WA. 2015. Modifiable and Non Modifiable Risk Factors of Stroke: A Review Update. $J$ Natl Inst Neurosci Bangladesh 1(1):22-26. Doi:10.3329/jninb.v1i1.22944.

10. Banerjee C, Moon YP, Paik MC, Rundek T, Mora-McLaughlin C, Vieira JR, et al. 2012. Duration of Diabetes and Risk of Ischemic Stroke: The Northern Manhattan Study. Stroke 43(5):1212-7. Doi: 10.1161/STROKEAHA.111.641381.

11. Shah RS, Cole JW. 2010. Smoking and Stroke: The More You Smoke The More You Stroke. Expert Rev Cardiovasc 8(7): 917-32. Doi: 10.1586/erc.10.56

12. Das SM, Sarkar A, Pramanik S, Bandyopadhyay A, Mondal K, Singh SK. 2013. Carotid Artery Intima-Media Thickness in Patients with Acute Ischemic Stroke and Its Correlation with Risk Factors for Atherosclerosis and/or Stroke. Asian Journal of Medical Sciences 6(1).

13. Sahoo R, Khisna MV, Subrahmanian DKS, Dutta TK, Elangovan S. 2009. Common 
Shita Febriana et.al. Atherogenic index profile on ischemic stroke patients at neurology department, Dr Soetomo Surabaya: a retrospective study.

Carotid Intima-Media Thickness in Acute Ischemic Stroke: A Case Control Study. Neurology India 57(5):627-630. Doi:10.4103/0028-3886.57822

14. Hollander M, Hak AE, Koudstaal PJ, Bots ML, Grobbee DE, Hofman A. et al. 2003. Comparison Between Measures of Atherosclerosis and Risk of Stroke: The Rotterdam Study. Stroke 34(10):2367-72. Doi:10.1161/01.STR.0000091393.320 60. OE

15. Martinic-Papovic I, Simundic AM, Dukic L, Lovrencic-Huzjan A, Popovic A, Seric V, et al. 2014. The Association of Inflammatory Markers with Cerebral Vasoreactivity and Carotid Atherosclerosis in Transient Ischaemic Attack. Clinical Biochemistry Journal 47(16):182-6. Doi:10.1016/j.clinbiochem.2014.0 7.010

16. Hoshi T, Kitagawa K, Yamagami H, Furukado S, Hougaku H, Hori M. 2007. Relation Between Interleukin-6 Level and Subclinical Intracranial Large-Artery Atherosclerosis. Atherosclerosis 197:32632. Doi:10.1061/j.atherosclerosis.200 7.05. 013.

17. Rubio-Guerra AF, Vargas-Robles H, Serrano AM, Lozano-Nuevo JJ, EscalanteAcosta BA. 2009. Correlation Between the Level of Circulating Adhesion Molecules and Atherosclerosis in type 2 Diabetic
Normotension Patients. Cell Adh Migr 3(4):369-72.

18. Larsson PT, Hallerstam S, Rosfors S, Wallen NH. 2005. Circulating Markers of Inflammation are Related to Carotid Artery Atherosclerosis. Int Angiol 24(1):43-51.

19. Kim BJ, Kim JS. 2014. Ischemic Stroke Classification: An Asian View Point. Journal of Stroke 16(1):8-17. Doi: 10.5853/jos.2014.16.1.8.

20. Kim JS, Nah HW, Park SM, Kim SK, Cho $\mathrm{KH}$, Lee J, et al. 2012. Risk Factors and Stroke Mechanism in Atherosclerotic Stroke: Intracranial Compared With Extracranial and Anterior Compared With Posterior Circulation Disease. Stroke 43:3313-18. Doi:10.1161/ STROKEAHA.112.658500.

21. Sujatha R, Kavitha S. Atherogenic indices in stroke patients: A retrospective study. Iran J Neurol. 2017;16(2):78-82.

How to cite this article: Febriana S, Ardhi MS. Atherogenic index profile on ischemic stroke patients at neurology department, Dr. Soetomo Surabaya: a retrospective study. International Journal of Research and Review. 2021; 8(11): 332-336. DOI: https://doi.org/10.52403/ijrr. 20211141 